\title{
Turismo e Produção do Espaço na Cidade do Rio de Janeiro
}

\author{
Tourism and Production of Space in the City of Rio de Janeiro
}

\section{Turismo y Producción de Espacio en la Ciudad de Rio de Janeiro}

\author{
Telma Mara Bittencourt Bassetti Santos ${ }^{1}$ \\ Maria Jaqueline Elicher ${ }^{2}$
}

\begin{abstract}
Resumo
Turismo é uma atividade que deve ser considerada em toda sua complexidade e contradição já que se trata, ao mesmo tempo, de uma atividade econômica assentada em um sistema de mercado capitalista, e por isso, sujeito aos seus efeitos; e uma prática social. Enquanto atividade econômica, o turismo se encontra no bojo do empreendedorismo urbano que vê na atividade um aporte ao crescimento econômico escondido sob os aspectos ideológicos do desenvolvimento. Este trabalho propõe uma análise e uma reflexão sobre as estratégias do capital para promover a (re) produção do espaço na cidade do Rio de Janeiro e sua transformação em lugar turístico visando a sua reprodução a partir da criação de espaços específicos para usos destinados ao lazer. Nesta direção, o turismo como aporte ao desenvolvimento aparece impregnado de aspectos ideológicos e, portanto, limitado à construção de espaços desiguais, já que assentado em um sistema de mercado que tem em sua essência a produção de desigualdades. A área de análise é a zona portuária do Rio de Janeiro que passa atualmente por intenso processo de (re) estruturação urbana e paisagística, a fim de atender as necessidades de reinserção da cidade nos atuais circuitos internacionais do capital, aproveitando o bojo dos megaeventos esportivos. Para realizar este trabalho, fizemos algumas visitas na zona portuária para produção das imagens e observações empíricas, bem como algumas entrevistas no morro da Providência a fim de investigar os desdobramentos da iniciativa do governo na vida cotidiana de seus moradores, de transformar a área do porto em área turística.
\end{abstract}

Palavras Chave: Turismo, Produção do Espaço, Lazer, Zona Portuária, Rio de Janeiro.

\begin{abstract}
Tourism is an activity that should be considered in all its complexity and contradiction as it is, while a seated economic activity in a capitalist market system, and therefore subject to its effects, and a social practice. While economic activity, tourism is in the midst of urban

\footnotetext{
${ }^{1}$ Doutora em Geografia Humana pela Faculdade de Filosofia, Letras e Ciências Humanas da Universidade de São Paulo (FFLCH-USP). Mestre em Ciência Ambiental pela Universidade Federal Fluminente (UFF). Graduada em Turismo pelo Centro Universitário Vila Velha (UVV). Professora adjunta do Curso de Turismo da Universidade Federal do Estado do Rio de Janeiro (UNIRIO). Brasil. telmabbassetti@ hotmail.com

2 Doutoranda em Geografia: Ordenamento Territorial pela UFF. Mestre em Geografia: Desenvolvimento Regional e Urbano pela Universidade Federal de Santa Catarina (UFSC). Bacharel e Licenciada em Geografia pela UFSC. Professora titular do Curso de Turismo da UNIRIO. Brasil. queijocmelado@ hotmail.com
} 
entrepreneurship activity that sees a contribution to economic growth hidden under the ideological aspects of development. This paper proposes an analysis and reflection on the strategies of the capital to promote the (re) production of space in the city of Rio de Janeiro and its transformation into a tourist place, targeting its reproduction from the creation of spaces for specific uses intended for leisure. In this direction, the contribution of tourism as a development appears imbued with ideological aspects and therefore limited to the construction of unequal spaces, as seated in a market system that has at its core the production of inequalities. The analysis area is the port area of Rio de Janeiro which is currently experiencing intense process of (re) structuring urban and landscape in order to meet the rehabilitation needs of the city's present international circuits of capital, cathcing the opportunities of mega sports events. To perform this work, some visits were made in the port area for the production of images and empirical observations and interviews were conducted on the Morro da Providência (Providência Hill) to investigate the consequences of the government's initiative in daily life of its residents, to transform the area port in tourist area.

Keywords: Tourism, Production of Space, Leisure.

\section{Resumen}

El turismo es una actividad que debe ser considerada con toda su complejidad y la contradicción de si misma, a su vez como una actividad económica asentada en un sistema de mercado capitalista y por lo tanto sujeto a sus efectos; además de una práctica social. En cuanto una actividad económica, el turismo se encuentra al centro del emprendimiento urbano que ve en esta actividad un aporte al crecimiento económico escondido bajo los aspectos ideológicos del desarrollo. En este trabajo se propone un análisis y reflexión sobre las estrategias del capital para promover la (re) producción del espacio en la ciudad de Río de Janeiro y su transformación en un lugar turístico orientado a su reproducción a partir de la creación de espacios destinados específicamente al ocio ${ }^{3}$. En este sentido, la contribución del turismo al desarrollo aparece impregnada de aspectos ideológicos y por lo tanto se limita a la construcción de espacios desiguales, esto debido a que se encuentra basado en un sistema de mercado que tiene como esencia la producción de desigualdades. El área de análisis es la zona portuaria de Río de Janeiro, la cual actualmente está experimentando un intenso proceso de reestructuración urbana y paisajística con el fin de satisfacer las necesidades de rehabilitación de los actuales circuitos internacionales de la ciudad de capital, aprovechando los próximos acontecimientos deportivos. Para llevar a cabo este trabajo, realizamos visitas a la zona portuaria para la recolección de imágenes y observaciones empíricas, así como algunas entrevistas en la zona del Morro da Providência a fin de investigar las consecuencias de la iniciativa del gobierno en la vida cotidiana de sus habitantes, para transformar el área del puerto en una zona turística.

Palavras Chave: Turismo, Producción de espacio, Ocio, Línea de Costa, Rio de Janeiro.

\footnotetext{
${ }^{3}$ Importante considerar que, em espanhol ócio é o termo designado para definir lazer. Em inglês, lazer aparece como entretenimento. Em português, lazer, entretenimento, recreação e ócio são termos distintos com diferentes significados.
} 


\section{Introdução}

Turismo é uma atividade que deve ser considerada em toda a sua complexidade e contradição já que se trata, ao mesmo tempo, de uma atividade econômica assentada em um sistema de mercado, o capitalismo, e aí sujeito aos seus efeitos; e uma prática social.

Enquanto atividade econômica, o turismo se encontra no bojo do empreendedorismo urbano que vê na atividade um aporte ao crescimento econômico escondido sob os aspectos ideológicos do desenvolvimento. Trata-se de uma estratégia urbana que, a partir da organização do espaço para transformação da cidade em lugar turístico, justifica a (re) produção do espaço levando em consideração a obtenção de lucros e a criação de espaços para usos específicos, neste caso: o lazer, para uma parcela restrita da população e para o turista. Nesta direção, o turismo como aporte ao desenvolvimento aparece impregnado de aspectos ideológicos e, portanto, limitado à construção de espaços desiguais, já que assentado em um sistema de mercado que tem em sua essência a produção de desigualdades.

Desmistificando o romantismo exagerado atribuído ao turismo, no sentido de que ele por si só gera desenvolvimento, Coriolano (2006) afirma que,

O discurso sobre o turismo é situado como opção para o desenvolvimento dos países, estados e municípios. Mas, na prática, é uma super-estimação de seu desempenho, criando falsas expectativas, sem possibilidades de solução aos problemas sociais e ambientais existentes. Pois não desenvolveu as regiões pobres, nem distribuiu a riqueza do país, além de não consolidar territórios, apenas organizar outros. Acrescentou problemas onde foi tratado como política para atender a acumulação capitalista em detrimento das necessidades básicas dos trabalhadores locais. Transformou o espaço em mercadoria global, desvalorizando o uso pela troca (CORIOLANO, 2006, p. $372)$.

Como podemos perceber na afirmativa de Coriolano, o turismo, assim como o capital, ao se desenvolver, age com violência nos lugares onde se realiza, desarticulando o espaço de maneira a produzir esse mesmo espaço conforme suas regras e suas leis. São vários os aspectos que dão suporte à definição do turismo, os quais, atrelados à realidade social vigente, nos ajudam a pensar a atividade com mais propriedade. Turismo pode ser considerado uma prática social que envolve o deslocamento de pessoas no tempo e no espaço, cujo 
desdobramento se dá no espaço de maneira dialética. Isso por que, segundo Coriolano (2006, p. 368), “enquanto prática social é também econômica, política, cultural e educativa, envolvendo relações sociais e de poder entre residentes e turistas, produtores e consumidores".

Contudo, uma prática social assentada em um sistema de mercado capitalista e, por isso, submetida à sua lógica. Isso porque, por maior que seja a vontade ou o desejo do indivíduo de realizar lazer em seu estado mais puro, ou seja, descomprometido com os aspectos mercadológicos que o norteiam, este lazer está inserido em um contexto maior e organizado de relações sociais de produção. Para Lefebvre (2001, p. 179), desde as épocas burguesas, os lazeres estão "subordinados exclusivamente à mais-valia, pelo viés da industrialização e da comercialização dos lazeres e dos espaços de lazer". Para que alguém realize lazer, em determinado lugar, é necessário que outro trabalhe de maneira a dar condição para que este lazer se realize. Este aspecto contraditório aponta para o fato de que lugares de lazer são, também, ao mesmo tempo, lugares de trabalho.

O que não significa dizer que os trabalhos gerados pelo turismo justifiquem sua implantação como aporte ao desenvolvimento ${ }^{4}$ tendo em vista que os trabalhos no campo do turismo empregam pessoas com baixa qualificação cujo desdobramento se dá na baixa remuneração e na sobrecarga de trabalho. Evidente que estamos nos referindo a lugares organizados e voltados para o lazer.

Ainda segundo Lefebvre,

o turismo é considerado uma indústria, porque os lazeres entram assim na divisão do trabalho social, não só porque o lazer permite a recuperação da força de trabalho, mas também porque passa a haver uma indústria dos lazeres, uma vasta comercialização dos espaços especializados, uma divisão do trabalho social projetada no território, e que entra na planificação global (LEFEBVRE, 1977, p. 247).

\footnotetext{
${ }^{4}$ As relações de trabalho no setor de turismo revelam que trabalhar nessa área não é garantia de bons salários, ao contrário. Embora prevaleçam no setor os ocupados com maior faixa etária, do sexo masculino, com maior estabilidade no emprego e com jornada de trabalho completa, ao se comparar o perfil dos empregados em atividades turísticas com o do total dos trabalhadores com carteira assinada do país, o salário médio no turismo é $14,7 \%$ inferior ao do conjunto dos empregados formais. Além disso, as atividades turísticas empregam proporção maior de pessoas com até a oitava série comparativamente ao total dos trabalhadores formais brasileiros e uma proporção menor de pessoas com o ensino médio e superior, ou seja, os níveis mais baixos de escolaridade. (http://www.ipea.gov.br, consulta em 08.05.2012).
} 
A velha abordagem sobre o turismo ser ou não uma indústria (neste caso, uma indústria sem chaminés) tendo como pressupostos básicos o fato de ser uma prestação de serviços ou ainda porque fabrica produtos intangíveis, só superficializa o debate e desvia a atenção dos efeitos que o turismo gera para a população residente nos lugares onde ele se realiza. Lefebvre está se referindo, ao contrário do que dissemos acima, à produção do espaço, mais especificamente à (re) produção das relações sociais de produção de maneira ampla. Segundo Lefebvre (2008), vincular a produção do espaço, de maneira geral, e do espaço urbano em particular, à reprodução dos meios de produção tendo em vista a força de trabalho perdeu o seu sentido com o fim do capitalismo concorrencial. O que significava reproduzir materialmente os meios de produção (máquinas e força de trabalho) e permitir o consumo de produtos a partir de sua compra no mercado. Para o autor, o sistema contratual expresso pelo contrato de trabalho e o sistema jurídico expresso pelo código civil e o código penal quase bastavam para assegurar, a partir da venda da força de trabalho, a reprodução dos meios de produção.

Nessa perspectiva, para Lefebvre (2008), o espaço era apenas funcional e instrumental. A cidade tinha por função principal, dentre outras, a de consumo, complementar à produção. $\mathrm{Na}$ argumentação de Lefebvre (2008),

a situação mudou: o modo de produção capitalista deve se defender num front (grifo do autor) muito mais amplo, mais diversificado e mais complexo, a saber: a re-produção das relações de produção. Essa reprodução das relações de produção não coincide mais com a reprodução dos meios de produção; ela se efetua através da cotidianidade, através dos lazeres e da cultura, (...), através das extensões e proliferações da cidade antiga, ou seja, através do espaço inteiro (LEFEBVRE, 2008, p. 48).

O que significa dizer que Lefebvre está apontando o espaço como essencialmente ligado à reprodução das relações sociais de produção. Não ao conceito de modo de produção, que no olhar do autor, foi reduzido e engessado a um sistema que destruiu a perspectiva de Marx. Para o autor, "sobrepor o modo de produção às relações de produção como coerência à contradição, essa atitude de uma "prática teórica" tomada em separado tem apenas um sentido: liquidar as contradições, excluir os conflitos (ou pelo menos certos conflitos essenciais), camuflando o que sucede e o que procede desses conflitos" (LEFEBVRE, 1977, p. 233). Mas, o esforço de Lefebvre (1977) está no sentido de afirmar que nunca existe um sistema acabado, antes, caminha na direção da sistematização, da coerência e da coesão, 
incluindo aqui a dialética, a partir das relações de produção e das suas contradições. Em outros termos, nas palavras do autor, trata-se "da capacidade do capitalismo para se manter, passados os seus momentos críticos" (LEFEBVRE, 1977, p. 238).

Desta maneira que, na análise do autor, o capitalismo transformou os elementos da sociedade (a cultura, os lazeres, o conhecimento, o cotidiano) apropriando-os para o seu uso. O capitalismo não subordinou apenas a si próprio, setores exteriores e anteriores, mas produziu setores novos transformando o que existia, remanejando as organizações e as instituições correspondentes. É o que se passa, na perspectiva de Lefebvre (1977), com a arte, com o saber, com os lazeres, com a realidade urbana e com a realidade cotidiana. Lefebvre elucida seu argumento a partir da devastação de obras e estilos e sua transformação em objetos de produção e de consumo ditos culturais. No entender do autor,

a produção capitalista retoma estes estilos como restituição e reconstituição, como "neo" isto ou "neo" aquilo, como obras de elite e produtos de alta qualidade. Não é apenas toda a sociedade que se torna o lugar da reprodução (das relações de produção e não já apenas dos meios de produção): é todo o espaço. Ocupado pelo neocapitalismo, setorizado, reduzido a um meio homogêneo e, contudo, fragmentado, reduzido a pedaços (só se vendem pedaços de espaço às "clientelas"), o espaço transforma-se na sede do poder (LEFEBVRE, 1977, p. 247).

Nesta direção, um espaço homogêneo e desarticulado englobando uma produção em seu sentido mais amplo: a produção de relações sociais e (re) produção de determinadas relações, "é nesse sentido que o espaço inteiro torna-se o lugar dessa reprodução, aí incluídos o espaço urbano, os espaços de lazeres, os espaços ditos educativos, os da cotidianidade, etc" (LEFEBVRE, 2008, p. 49). Chamamos atenção para os espaços de lazeres e seu papel na (re) produção das relações sociais de produção. Para Lefebvre (2008), os espaços de lazeres são dissociados da produção, de tal maneira que parecem, em um primeiro momento, como espaços independentes do trabalho e, portanto, livres. Contudo, estes espaços encontram-se fortemente ligados aos setores do trabalho no consumo organizado e no consumo dominado.

Ainda, para Lefebvre (2008), embora aparentemente separados da produção, esses espaços estão atrelados ao trabalho produtivo, embora sejam considerados lugares da recuperação. Nesta direção, nas palavras do autor, 
tais lugares, aos quais se procura dar um ar de liberdade e de festa, que se povoa de signos que não têm a produção e o trabalho por significados, encontram-se precisamente ligados ao trabalho produtivo. (...) São precisamente lugares nos quais se reproduzem as relações de produção, o que não exclui, mas inclui, a reprodução pura e simples da força de trabalho. Tudo isso se lê nesses espaços, mas com dificuldades, pois o texto e o contexto estão embaralhados (como num rascunho) (LEFEBVRE, 2008, p. $50)$.

Assim o tempo livre e os lazeres são submetidos a uma lógica racionalizada fortemente vinculada à capacidade individual de consumo, limitando ou possibilitando ao indivíduo o direito à cidade e, inserido neste universo, à utilização do tempo livre para realização de práticas de lazer.

Assim como o turismo, cada vez mais o lazer está submetido a uma relação de consumo. Façamos uso das palavras saudosas de Lefebvre quando questiona: "os lazeres? (...) o que havia? As boas e velhas distrações, os divertimentos e as atrações artísticas, as festas tradicionais, as danças e os bailes de máscaras" (LEFEBVRE, 1977, p. 246). Ao apontar o lazer inserido em um contexto específico, o autor está se referindo a um momento histórico que antecedeu o processo seguido pelo capitalismo no decurso de sua transformação e na transformação desses elementos sociais, isto é, desses lazeres, em mercadoria, em valores de troca. Contudo, é o mesmo Lefebvre que nos chama atenção para o fato de que o tempo, independente de sua qualidade, está inserido na (re) produção das relações sociais de produção, logo, na produção do espaço, e submetido à lógica da reprodução do capital em escala ampliada. Em suas palavras,

(...) o tempo, bem supremo, mercadoria suprema, se vende e se compra: tempo de trabalho, tempo de consumo, de lazer, de percurso etc. Ele se organiza em função do trabalho produtivo e da reprodução das relações de produção na cotidianidade. O tempo "perdido" não o é para todo mundo, pois é preciso pagar caro por ele. O pretenso "tempo livre" é apenas o tempo imposto, aquele dos transportes e das formalidades, já se sabe como ele se vincula de maneira descolada ao tempo de trabalho (LEFEBVRE, 2008, p. $50)$.

O turismo se realiza no espaço, o qual está atrelado ao tempo. Não só pela utilização qualitativa do tempo, tempo de trabalho, tempo de lazer, tempo do nada fazer, embora aqui apresentado de maneira utópica; mas o tempo consumido, ou gasto, necessário à possibilidade 
de consumir esse mesmo tempo, em outro lugar, de outra maneira. Não podemos esquecer que a aceleração do tempo decorrente do ritmo acelerado do capital acaba por sujeitar à sua lógica a aceleração do tempo de lazer bem como o esvaziamento das práticas de lazer limitando tais práticas a uma dimensão de consumo.

O uso ou o consumo do tempo acaba por produzir o espaço. Ana Fani Alessandri Carlos, utilizando Lefebvre como aporte teórico elucida bem essa questão:

as relações sociais possuem existência real como existência espacial concreta na medida que produzem, efetivamente, um espaço, aí se inscrevendo e se realizando. As relações sociais ocorrem em um lugar determinado, sem a qual não se concretizariam, em um tempo fixado ou determinado que marcaria a duração da ação. É assim que espaço e tempo aparecem por meio da ação humana em sua indissociabilidade, uma ação que se realiza como modo de apropriação (CARLOS, 2001, p. 13).

Outra característica que ajuda a definir a atividade turística diz respeito ao conflito entre vida cotidiana e turismo nos lugares onde o turismo se realiza. Lugares turísticos nunca podem ser entendidos, apenas, como lugares de passagem a ponto de excluirmos dali a vida cotidiana. Assim, lugares turísticos, em um primeiro olhar, podem ser definidos como lugares de lazer para uns, de trabalho para outros e da vida cotidiana para outros ainda ${ }^{5}$. Assim, o turismo está sempre concorrendo com a vida cotidiana que se realiza nesses mesmos lugares. "Viver é sempre mais que simplesmente fazer turismo ou receber turistas", afirma Cruz (2007, p.6).

A afirmativa de Cruz nos remete a Carlos (2008) no que diz respeito à explicação de determinado fenômeno, neste caso o turismo, sob o olhar da geografia. Para Carlos, trata-se de olhar determinado fenômeno a partir da espacialidade, "da dimensão espacial da realidade social; o papel do espaço na (re) produção da vida humana" (CARLOS, 2008, p. 21). Esta perspectiva de análise, defendida por Carlos (2008), coloca o homem como elemento central na discussão da produção do espaço. E ainda, o homem, segundo a autora,

em condições e situações sociais e históricas específicas, como ser, cuja humanidade foi produzida ao longo da história, e que se realiza no processo de reprodução da vida.

\footnotetext{
${ }^{5}$ Em nossa dissertação de mestrado, argumentamos sobre interesses diferenciados que residentes e turistas têm sobre os mesmos recursos. Para o turista, interessa o atendimento de suas necessidades imediatas relacionadas ao consumo. Para o residente, mais importante é a manutenção da vida cotidiana (SANTOS, 2004).
} 
Nessa perspectiva, o homem coloca-se como criador do mundo e produto da sociedade; sua vida individual é a vida genérica, que se produz na práxis humana compreendida como processo de transformação de si próprio. No cerne desse processo está a relação com o mundo e consigo mesmo, a partir do trabalho, como processo consciente, na medida em que é ele que transforma a realidade objetiva (entendida como natural e social), na construção da própria realidade humana (CARLOS, 2008, p. 21).

A produção do espaço pelo turismo é resultado do embate múltiplo e concomitante de interesses diferenciados entre turistas e residentes e do trabalho que deste embate é resultado, quer dizer, trabalho para gestão do turismo organizado e trabalho para gestão da vida, desvinculado do turismo. Isso porque, mesmo em lugares turísticos, a vida se realiza, a despeito do desenvolvimento desta atividade, para muitas pessoas.

Outra questão que se impõe é a relação confusa entre equipamentos de lazer utilizados pelos residentes de um determinado lugar, e a utilização destes mesmos equipamentos pelos turistas. Coriolano nos chama atenção para o fato de que, "o turismo dotou-se de uma carga ideológica tão forte que arrastou consigo outras atividades inclusive o lazer dos moradores locais. Em sua essência, turismo é lazer, mas lazer com viagem." (CORIOLANO, p. 42, 2006). A autora ressalta que da mesma maneira que nem todo lazer é turismo, nem toda viagem é turística. Vejamos porque, o carioca que mora em Copacabana e freqüenta a praia durante o final de semana e usufrui dos bares e restaurantes da orla, está apenas consumindo lazer. No entanto, essas mesmas atividades, se realizadas por um visitante, podem ser caracterizadas como consumo de serviços turísticos. Sobre a segunda afirmativa, já dissemos que turismo é o casamento entre viagem e lazer. Sendo assim, qualquer viagem que não esteja relacionada ao lazer não pode ser considerada turística. Neste caso, são realizadas práticas turísticas, porque há deslocamento no tempo e no espaço, mas não obrigatoriamente, turismo.

O problema não está nos usos diferenciados que turistas e residentes fazem dos mesmos equipamentos de lazer distribuídos pela cidade, mas na escolha política que se faz ao priorizar a construção desses mesmos equipamentos. Sobretudo com participação de políticas públicas, valorizando os turistas em detrimento dos residentes, o que implica uma perspectiva de consumo ao invés de um lazer público e emancipatório.

Chauí argumenta que os seres humanos necessitam vitalmente do lazer e do entretenimento, 
seja, como mostrou Marx, para que a força de trabalho aumente a sua produtividade, graças ao descanso, seja, como mostram estudiosos marxistas, para que o controle social e a dominação se perpetuem por meio da alienação, seja, como assinala Arendt, porque o lazer e o entretenimento são exigências vitais do metabolismo humano. (CHAUÍ, 2006, p.20).

Seguindo a argumentação de Chauí (2006), a despeito das concepções do entretenimento, sua principal característica não é apenas o repouso, mas também o passatempo. Nas palavras da autora,

o passatempo ou o entretenimento dizem respeito ao tempo biológico e ao ciclo vital de reposição de forças corporais e psíquicas. O entretenimento é uma dimensão da cultura tomada em seu sentido amplo e antropológico, pois é a maneira como uma sociedade inventa seus momentos de distração, diversão, lazer e repouso. (CHAUÍ, 2006, p.21).

Nesta obra, Chauí está discutindo a relação entre o simulacro e o poder e o papel do mass media na produção deste simulacro enquanto instrumento de poder. Segundo a autora, há uma perda de qualidade na divulgação dos fatos pela mídia, os quais são transformados em simulacros e entretenimento. Assim, os fatos noticiados em forma de espetáculo são transformados em simulacros, exercendo a função de entretenimento. Para os propósitos deste trabalho, é o entretenimento, proveniente do simulacro, e, também, utilizado como lazer, que nos interessa. Isso porque o turismo, enquanto atividade econômica, não só se apropria dos equipamentos de lazer existentes no espaço, como, também, cria estes equipamentos como condição, meio e produto de sua própria realização. Isso porque, como dissemos, o turismo se realiza no espaço produzindo e reproduzindo este mesmo espaço.

Desta maneira, lazer e turismo, juntos, sob a égide do desenvolvimento, vão justificando os projetos econômicos para a produção do espaço na cidade do Rio de Janeiro, delegando ao turismo um poder que ele, sozinho, não tem, qual seja: o de gerar desenvolvimento nos lugares onde ele se realiza. Isso porque o planejamento do turismo, por si só, não é garantia de melhoria de condições de vida para todos os residentes, tendo em vista que existem planejamentos voltados para a produção e reprodução do capital, mesmo que ideologicamente mascarados pelo discurso do desenvolvimento para todos tendo o turismo como aporte. 


\section{Turismo e Gentrificação na Zona Portuária da Cidade do Rio de Janeiro}

O recente projeto de produção do espaço na cidade do Rio de Janeiro visa preparar a cidade para atender aos diversos eventos de caráter esportivo para os quais será sede. Para tanto, a cidade obedece a um movimento maior, que é da competição entre os lugares, sob a pretensa promoção do desenvolvimento, cujo objetivo primeiro é atender as novas demandas de turistas interessados em consumir os eventos esportivos e a cidade.

A competição dos lugares para ingressar no rol dos destinos turísticos nacionais e internacionais, insere hoje, principalmente, os chamados países em desenvolvimento, considerados mercados de grande potencial para o crescimento do setor. Segundo CRUZ (2006), esta inserção se coloca como uma tarefa das mais difíceis, pois os lugares precisam se preparar, conjugando fatores de ordem externa e interna, que alia capital privado e público. Trata-se de um pacto que ao final das contas dá maior visibilidade ao lugar a fim de que se atraiam os investidores privados.

A competitividade internacional depende das qualidades e quantidades de recursos materiais e humanos que cada lugar tem a oferecer. Segundo Harvey (2005), isso significa um inserção diferenciada dentro da divisão internacional do trabalho a partir da criação da exploração de vantagens específicas para a produção de bens e serviços. Mesmo que, na contrapartida, essas ações se construam sobre divergências de interesses entre os sujeitos sociais diretamente envolvidos e produzam pobreza, exclusão e destruição ambiental (Cruz, 2006).

Nessa ótica o Estado é historicamente um agente da promoção do capital, embora clivado pelas lutas de classe. Numa perspectiva gramsciana, este se metamorfoseia dependendo dos elementos e contextos históricos, variando de momentos em que deu um peso maior aos interesses dos trabalhadores, como no Estado de Bem Estar Social, ou em outros, que se impôs às suas ações a ótica mais liberal. Concordamos com Harvey (2005) de que não é recente o posicionamento do Estado enquanto agente central para o funcionamento do capitalismo, ao contrário, ele sempre esteve presente, apenas suas formas e modos de funcionamento mudaram conforme o próprio sistema amadureceu. No momento atual estamos tratando de um Estado estruturado em bases menos interventoras e de parcerias mais diretas frente às ações do capital. 
Em países como o Brasil esta nova configuração se dá, sobretudo, com a consagração do neoliberalismo nos anos 1990. Neste momento, se acompanha a estruturação de um Estado mais atuante e parceiro do mercado, que aporta em setores econômicos como o turismo as expectativas da geração do desenvolvimento (CRUZ, 2006). De lá pra cá, a atividade turística tem participado ativamente como um dos elementos centrais nos projetos de desenvolvimento e se insere como elemento motriz na competição acirrada dos lugares pela atração dos investimentos. No caso do Rio de Janeiro, a organização de eventos de ordem planetária, como os que se vislumbram para a próxima década, se configura como a estratégia atrativa.

O discurso sobre o turismo é situado como opção para o desenvolvimento dos países, estados e municípios. Mas, na prática, é uma super-estimação de seu desempenho, criando falsas expectativas, sem possibilidades de solução aos problemas sociais e ambientais existentes. Pois não desenvolveu as regiões pobres, nem distribuiu a riqueza do país, além de não consolidar territórios, apenas organizar outros. Acrescentou problemas onde foi tratado como política para atender a acumulação capitalista em detrimento das necessidades básicas dos trabalhadores locais. Transformou o espaço em mercadoria global, desvalorizando o uso pela troca. (CORIOLANO, 2006, p. $372)$.

No que concerne ao desenvolvimento do turismo, a atuação do Estado se dá, sobretudo, na garantia da infra-estrutura básica e na implementação de ações que aliem todas as esferas do poder público, no sentido de promover a melhor organização dos territórios para aumentar a fluidez dos mesmos e garantir que se fortaleçam as bases necessárias para a reprodução do capital. Segundo Cruz (2006, p. 338), “Tornar o território atrativo para o capital privado é o objetivo precípuo dessas ações." A garantia de certas tarefas básicas mínimas no apoio ao modo de produção capitalista de produção (HARVEY, 2005), possibilita pensar novas formas de planejamento das cidades, enquanto espaços supremos para a realização do capital.

No bojo de organização dos espaços para os grandes eventos é atribuído à cidade o caráter de mercadoria. Segundo Vainer (2000), é aí que se organiza um novo modelo de planejamento do espaço das cidades, que dá a elas não só o caráter da mercadoria, mas também o de empresa e pátria. As cidades estariam enfrentando os mesmos desafios das empresas, pois estão sendo submetidas às mesmas transformações destas.

$\mathrm{Na}$ realização de megaeventos internacionais estão implícitas oportunidades excepcionais de promoção das cidades no aprofundamento das suas relações com o turismo, já que na esteira 
dos megaeventos e até que estes se realizem muitos outros eventos vão consolidando a imagem de uma cidade boa para se realizar negócios. Nesse caminho, cidades como o Rio de Janeiro que são notadamente reconhecidas por seus atributos paisagísticos e culturais, ampliam as estratégias para a criação e a transformação dos espaços em áreas de lazer, como atividades específicas, para os turistas ${ }^{6}$, a exemplo do que acontecerá na zona portuária.

A zona portuária está em franco processo de transformação com a implementação do projeto Porto Maravilha, que visa promover profunda (re) estruturação do espaço urbano desta parte da cidade. Trata-se de um projeto que pretende relançar aos circuitos do capital uma gigantesca área inserida na área central do Rio de Janeiro, e que até pouco tempo pertencia à parte da cidade há muito "abandonada" pelo poder público e, por que não dizer, distanciada dos olhos do mercado.

Por ocasião da realização dos grandes eventos na cidade, a zona portuária se tornou área atrativa e passará a atender aos interesses de megainvestidores nacionais e internacionais que, num acordo com as esferas públicas, vão promover a remodelação dessa área, reinserindo a cidade no circuito internacional das cidades atrativas. Para tanto, espaços de moradia, lazer e comércio contemplam o grande projeto Porto Maravilha.

A estratégia de produção de espaços específicos para o lazer na zona portuária segue a necessidade de conciliar a garantia de reprodução do capital atendendo, de certa forma, a necessidades sociais ligadas à moradia, por exemplo. Desta maneira, na zona portuária da cidade carioca serão construídos prédios residenciais com características modernas, voltados para populações de classe média alta. Os prédios a serem construídos atendem a um alto padrão em termos de sofisticação e junto com eles serão erguidos hotéis cinco estrelas e centros de convenções, o que marca a revalorização da estrutura urbana, por anos abandonada. No entanto, obviamente não estamos falando de um lugar desabitado, ao contrário, os atuais moradores das comunidades da Providência, da Saúde e da Gamboa estão sistematicamente sendo removidos da zona portuária, como podemos observar na Figura 1 e 2.

\footnotetext{
${ }^{6}$ Importante considerar que apenas uma pequena parcela da população detém condições econômicas suficientes para realizar turismo ou atividades específicas de lazer ligadas ao consumo, o que explica o turismo enquanto elemento de diferenciação social.
} 


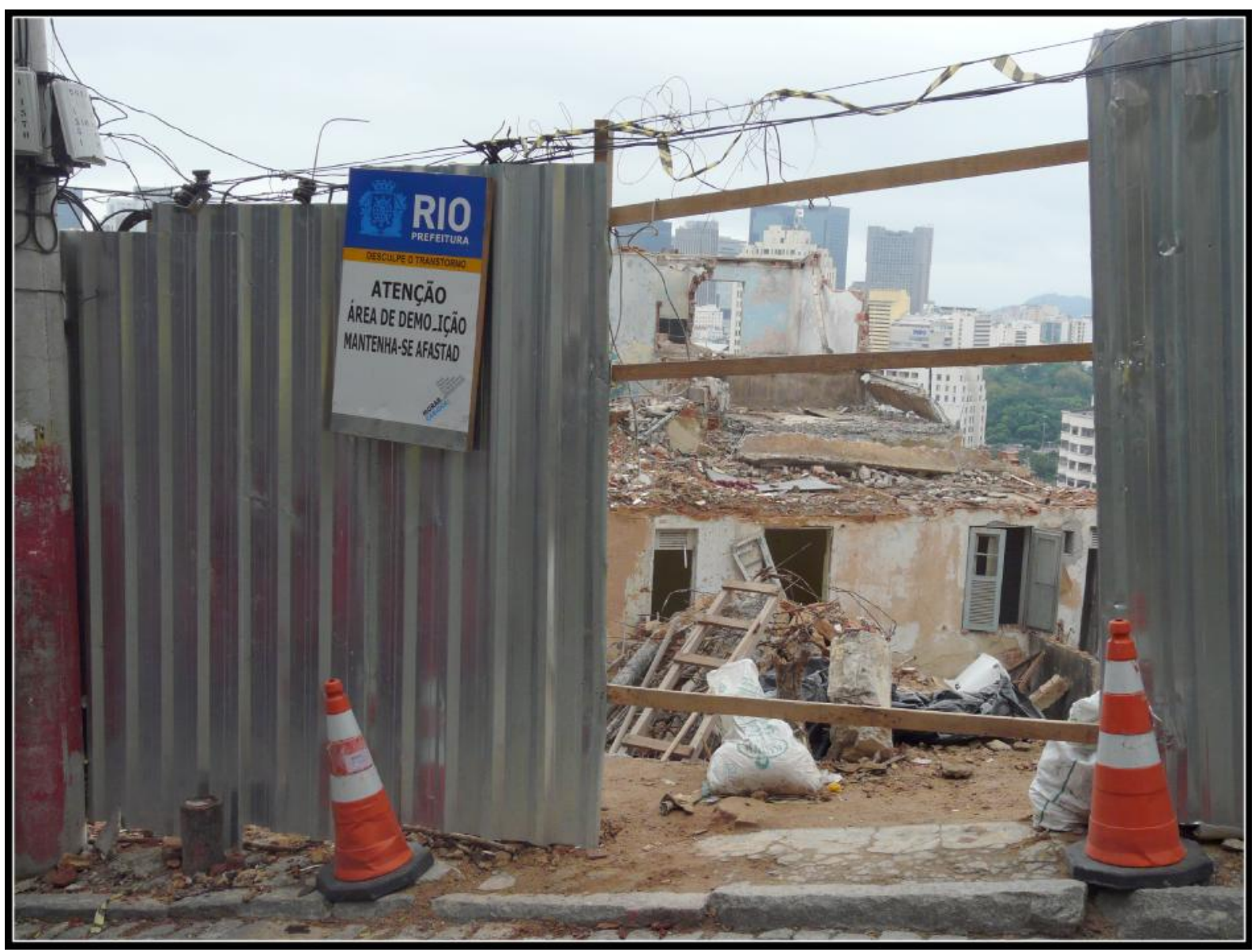

Figura 1: Demolição de casas no Morro da Providência Zona Portuária/Rio de Janeiro.

Fonte: Maria Jaqueline Elicher (acervo pessoal)

Os atuais residentes não são bem vindos ao olhar do turista e, também, não tem condições financeiras para se apropriarem das novas moradias que serão ali construídas. É preciso considerar que parte da remoção da favela foi feita a partir da necessidade de esconder do olhar do turista aquilo que não é para ser visto, neste caso, a pobreza. Assim, a decisão sobre o que ser removido na favela, ou não, foi baseada no alcance do olhar de quem está lá embaixo, no centro da zona portuária, então em processo de re-produção para novos usos. 


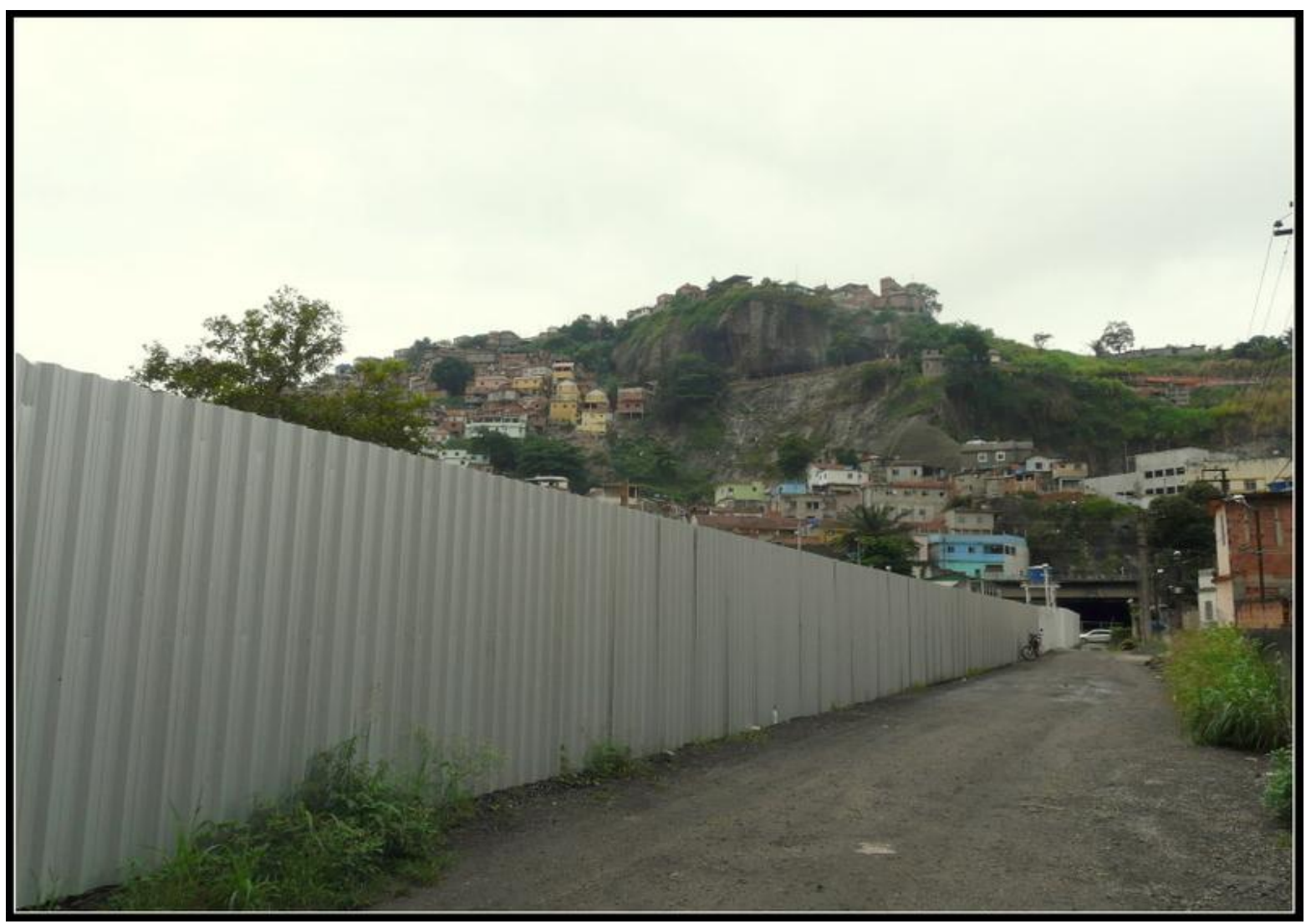

Figura 2: Instalação de obras de melhoria e Morro da Providência ao fundo Zona Portuária/Rio de Janeiro

Fonte: Maria Jaqueline Elicher (acervo pessoal)

Toda essa transformação na cidade não seria possível sem uma estratégia que envolvesse o apoio popular. Neste caso, a estratégia envolve a divulgação de imagens que sugerem a construção de um legado social a partir da melhoria do sistema de circulação e aumento das áreas de lazer na área, como é possível observar na imagem abaixo. O objetivo é penetrar na sociedade e convencê-la a apoiar os projetos, como é o caso sobre o que vem acontecendo com a produção de uma opinião pública bastante favorável ao Projeto Porto Maravilha.

Para tanto o Estado trabalha ativamente com a produção de imagens que possa agira na construção de uma opinião pública favorável, que possa legitimar sua atuação. Nessa direção, o processo se apresenta, aparentemente, democrático e participativo, como pode ser observado nas figuras 3 e 4 . Trata-se, na verdade, da construção de um senso comum baseado 
em um jogo de interesses para justificar a ação do Estado e do capital. Isso porque, desprezados pelo Estado, estão todos os moradores das favelas que estão sendo removidos, sem que haja qualquer diálogo com eles.

Figura 3

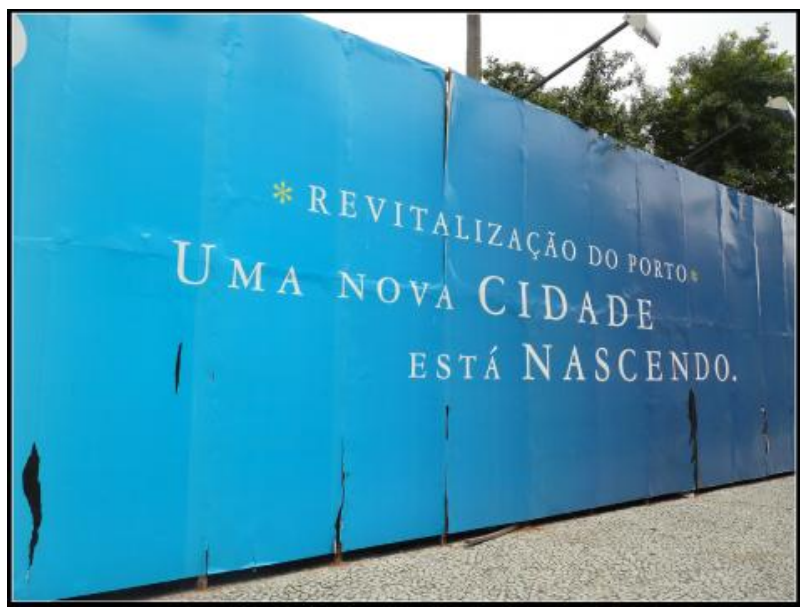

Figura 4

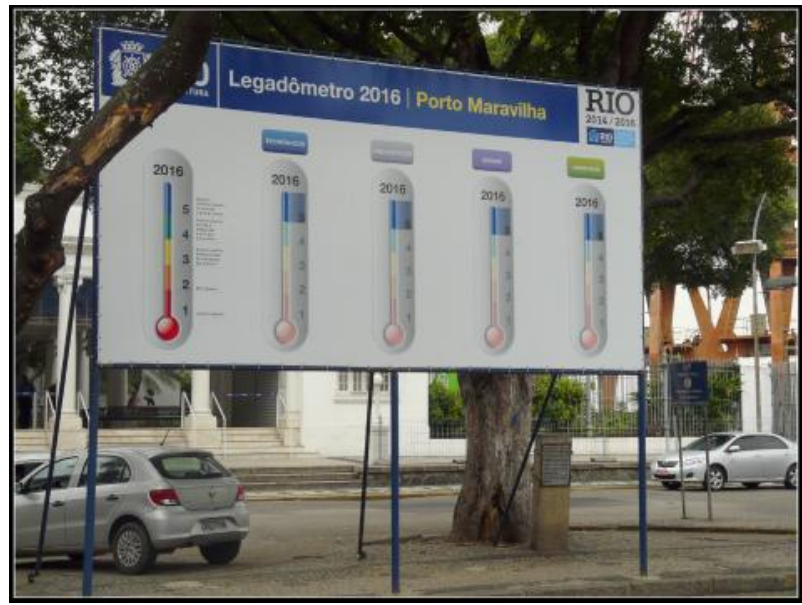

Figura 3 - Imagem que remete ao nascimento de uma nova cidade na Zona Portuária e Figura 4 - Legadômetro utilizado para passar a ideia de que a população está acompanhando atentamente as obras de (re) estruturação.

Fonte: Maria Jaqueline Elicher (acervo pessoal)

O que não se discute é a maneira como estas novas áreas incorporarão as necessidades gerais da população por novas áreas de lazer e entretenimento, já que se trata de áreas que tendem a possuir um caráter elitizado de acesso. $\mathrm{O}$ que acontece de fato é o desenvolvimento de um projeto que a priori é pensando para atender a uma nova demanda por habitação de uma classe já favorecida da sociedade. Além disso, o lazer é pensado para aqueles que irão morar nestas áreas, os novos residentes, e os turistas que certamente visitarão a cidade na época dos grandes eventos.

No arranjo político-econômico a cidade vai se sujeitando aos projetos e se comportando como um "ser" passivo, aparentemente desprovido das práticas sociais que são apontadas por Harvey (2005), como parte intrínseca do processo de organização dos espaços. Isso porque a urbanização funciona como um processo social espacialmente fundamentado, que abrange um 
leque de atores, com objetivos e compromissos diversos, que interagem por meio de uma configuração de práticas entrelaçadas (HARVEY, 2005, p. 170).

Considerando que sob o capitalismo o leque de práticas sociais em associação com a circulação do capital e a reprodução da força de trabalho esteja sob o controle do sistema e estes pareçam hegemônicos; é inegável que existam aspectos de ordem subjetiva que se impõe na cidade através dos seus moradores e das experiências os quais envolvem percepções, leituras simbólicas e aspirações destes para com o espaço que ocupam.

Em todos estes aspectos há uma tensão permanente entre forma e processo, entre objeto e sujeito, entre atividade e coisa. É tão insensato negar o papel e o poder das objetivações, da capacidade das coisas que criamos de retornar como formas de dominação, quanto é insensato atribuir, a tais coisas, a capacidade relativa á ação social (HARVEY, 2005, p. 170)

Na zona portuária do Rio podemos considerar que existe hoje uma massa de moradores invisíveis, moradores de rua, ou mesmo os moradores das comunidades pobres do entorno, que não estão contidos nos projetos de reestruturação urbana. E ainda, não serão contemplados com as novas moradias ou poderão ter acesso às novas áreas de lazer, pois estas não estão sendo pensadas para a classe baixa. Mas, contraditoriamente, como afirma Lefebvre, trata-se do espaço onde se realiza a reprodução das relações sociais, o que reflete no encarecimento da vida em todas as suas instâncias, e, porque não dizer, mais uma vez condicionando o acesso ao lazer à situação econômica. Trata-se de exaltar o conflito existente entre a vida cotidiana e suas necessidades de reprodução.

Não é recente a busca que a cidade do Rio de Janeiro realiza para se inserir de forma mais aprofundada nos circuitos turísticos. A cargo de uma pretensa natureza turística da cidade, o Estado tem trabalhado desde então para promover o desenvolvimento incentivando a produção do espaço para tal e ampliando cada vez mais sua visibilidade internacional. A base da preparação da cidade para consolidar seu ingresso no competitivo mercado internacional continua sendo o aprofundamento das relações da cidade com as suas imagens históricas. A partir da oferta de novos (antigos) espaços para uso do capital, a serem totalmente remodelados e retrabalhados paisagisticamente, a fim de se promover uma modernização e uma (re) significação nos seus usos. 
É neste bojo que se insere a área em questão, atualmente abarcada pelo projeto Porto Maravilha. E, neste sentido, é muito simbólica, pois marca a ocupação da cidade e também históricos espaços de oposição social. A zona portuária se fïrma como a presença mais marcante da cidade antiga, tradicional, atrasada, feia e suja, que se contrapõe a um Rio de Janeiro que já se buscava moderno, progressista, belo e higienizado, promessas de modernização urbana iniciadas com Pereira Passos, no século XIX (CRUZ, 1999).

É preciso refletir sobre os efeitos deste processo de (re) construção do espaço para conformação de novos usos e a maneira como eles se impõem. Sobretudo levando em consideração o fato de que se trata de um projeto de dimensões urbano-arquitetônicas grandiosas e que se cunha numa concepção de cidade que, a priori, parece impossível de se compatibilizar com a presença e manutenção dos grupos sociais instalados ali até o momento. Segundo Sanchez (2007, p.26), algumas experiências de renovação urbana têm promovido mais a gentrificação ${ }^{7}$, a valorização de capitais privados e a especulação imobiliária, do que a inclusão social e a melhoria das condições de vida dos que atualmente ocupam essas regiões.

Dentre as ações envolvidas pra a (re) funcionalização do porto está a recuperação do patrimônio histórico e cultural já existente, assim como o próprio equipamento do porto, com seus galpões e piers, e a implantação de novos equipamentos de lazer e entretenimento. Tratase de uma estratégia para (re) funcionalizar a área a partir das necessidades de uso daqueles que virão a ocupá-la, no movimento claro e evidente de inserção da "nova cidade" nos circuitos turísticos nacionais e internacionais. Em nenhum momento entendemos como um processo que visa recuperar a área e (re) funcionalizá-la para aqueles que hoje a ocupam, principalmente por se tratarem de uma parcela marginalizada da sociedade.

Nesta direção, o atual projeto de revitalização incorpora um espírito antigo de constante necessidade de mudança dessa área. Muitos outros projetos já foram pensados, mas apenas agora, por ocasião de uma comutação especial de forças e pela atual conjuntura, a revitalização da zona portuária do Rio irá acontecer.

As condições de uso das instalações portuárias acabam variando de acordo com o momento político e econômico pelo qual a cidade vai atravessar, dentro de um contexto econômico nacional e também internacional. Portanto, ao Porto se sucedem momentos de importância

\footnotetext{
${ }^{7}$ A construção do estádio de futebol do clube do Corinthians em Itaquera, bairro localizado na zona leste da cidade de São Paulo, tem promovido, de igual maneira, a gentrificação.
} 
econômica, com sua modernização e valorização, com momentos de abandono e obsolescência. O último deles ocorreu na década de 1970, por ocasião da mudança nas formas de operação das ações portuárias. Os espaços construídos, como galpões e armazéns perderam o sentido original de uso, que é o de estocagem de mercadorias e foram substituídos pelos modernos containers, imprimindo uma nova lógica na utilização do espaço do Porto.

As sucessivas crises à qual esteve sujeita a economia fluminense e toda a economia nacional, associado a perda de poder político e status administrativo, provocaram um arrefecimento das atividades portuárias do Rio de Janeiro, fato que também propiciou o abandono de muitas instalações.

Nesse movimento, a produção do espaço é, ao mesmo tempo, construção e destruição de formas e funções sociais dos lugares. Isso porque, a (des) construção do espaço não se refere apenas à destruição e à construção de objetos fixos, mas também às relações que os unem em combinações distintas ao longo do tempo. As antigas formas encontradas ainda hoje na zona portuária representariam essas rugosidades, como espaços testemunhos de um determinado momento de um modo de produção, porque possuem uma memória do espaço construído, das coisas fixadas na paisagem criada. Mas não só isso. Trata-se, além do que dissemos acima, da reprodução da vida e de uma vida, cuja reprodução, está cada vez mais condicionada a uma relação econômica.

Para Santos (1980, p. 138) "as rugosidades nos oferecem, mesmo sem tradução imediata, restos de uma divisão de trabalho internacional, manifestada localmente por combinações particulares do capital, das técnicas e do trabalho utilizados”. Mas, o espaço é uma forma durável, que não se desfaz paralelamente à mudança de processos, ao contrário, alguns processos se adaptam às formas pré-existentes, enquanto outros criam novas formas para se inserir dentro delas. Eles não desaparecem, mas podem e são (re) significados e a eles atribuídos novos usos. Em nome do turismo e do lazer elitizado esses novos usos se dão na cidade do Rio de Janeiro, como está sendo o caso do Porto Maravilha, a partir de uma relação de violência, já que retiram do olhar turístico tudo o que não é para ser visto.

Mais recentemente, espaços outrora abandonados estão sendo reincorporados à dinâmica urbana do Rio de Janeiro, tais como os antigos armazéns que foram transformados na Cidade do Samba e os armazéns culturais que têm sido palco de uma intensa agenda de eventos de 
magnitude nacional e internacional. Tais ações recolocam esses espaços, outrora degradados, no circuito dos usos cotidianos, num movimento que, segundo Sanchez (2007) propicia a promoção do encontro da cultura com a economia. A cultura é hoje parte decisiva do mundo dos negócios e, como grande negócio aparece como a nova mercadoria vedete desta rodada do capitalismo.

\section{Considerações Finais}

Todo esse processo a que nos referimos nos faz pensar sobre a noção de rugosidades presentes na teoria de Milton Santos. Para o autor, a produção do espaço é, ao mesmo tempo, construção e destruição de formas e funções sociais dos lugares. Isso porque, a (des) construção do espaço não se refere apenas à destruição e à construção de objetos fixos, mas também às relações que os unem em combinações distintas ao longo do tempo. As antigas formas encontradas ainda hoje na zona portuária representariam essas rugosidades, como espaços testemunhos de um determinado momento de um modo de produção, porque possuem uma memória do espaço construído, das coisas fixadas na paisagem criada. Mas não só isso. Trata-se, além do que dissemos acima, da reprodução da vida e de uma vida, cuja reprodução, está cada vez mais condicionada a uma relação econômica.

Para Santos (1980, p. 138) "as rugosidades nos oferecem, mesmo sem tradução imediata, restos de uma divisão de trabalho internacional, manifestada localmente por combinações particulares do capital, das técnicas e do trabalho utilizados”. Mas, o espaço é uma forma durável, que não se desfaz paralelamente à mudança de processos, ao contrário, alguns processos se adaptam às formas pré-existentes, enquanto outros criam novas formas para se inserir dentro delas. Eles não desaparecem, mas podem e são (re) significados e a eles atribuídos novos usos. Em nome do turismo e do lazer elitizado esses novos usos se dão na cidade do Rio de Janeiro, como está sendo o caso do Porto Maravilha, a partir de uma relação de violência, já que retiram do olhar turístico tudo o que não é para ser visto.

O artigo aponta para o fato de que a (re) produção do espaço tendo o turismo como aporte está inserido em um processo maior que diz respeito a (re) produção do capital em escala ampliada. Isso porque produz desigualdades aumentando a distância entre os indivíduos a partir de uma relação de classe. Nesta direção, o crescimento da pobreza, como 
desdobramento da reprodução do sistema capitalista indica exatamente a sua força. Não se trata, portanto, apenas de uma refuncionalização do espaço para usos turísticos, mas, sobretudo, dos efeitos desse processo na reprodução da vida cotidiana.

\section{Referências}

CARLOS, Ana Fani Alessandri. O turismo e a produção do não-lugar. In: CARLOS, Ana Fani Alessandri; YÁSIGI, Eduardo; CRUZ, Rita de Cássia Ariza (Orgs.). Turismo: espaço, paisagem e cultura. 2.ed. São Paulo: Hucitec, 1999.

2001.

Espaço-tempo na metrópole: a fragmentação da vida cotidiana. São Paulo: Contexto,

A (re)produção do espaço urbano. 1. ed. 1. reimpr. São Paulo: Editora da Universidade de São Paulo, 2008.

CASTRO, Celso. A natureza turística do Rio de Janeiro. In: BANDUCCI, Álvaro; BARRETTO, Margarita (Orgs.). Turismo e identidade local: uma visão antropológica. Campinas, SP: Papirus, 2001.

CHAUÍ, Marilena. Cidadania cultural: o direito à cultura. São Paulo: Editora Fundação Perseu Abramo, 2006. CRUZ, Rita de Cássia Ariza da. Geografias do Turismo: de lugares a pseudo-lugares. São Paulo: Roca, 2007.

CRUZ, Rita de Cássia A. da. Planejamento Governamental do turismo: convergências e contradições na produção do espaço. In: América Latina: cidade, campo e turismo. Org. Amália Inés G. de Lemos; Monica Arroyo y Maria Laura Silveira. 1ª Ed. Buenos Aires: Consejo Latinoamericano de Ciencias Sociales. CLACSO; São Paulo: USP, 2006.

CORIOLANO, Luzia Neide Menezes Teixeira. O turismo nos discursos, nas políticas e no combate à pobreza. São Paulo: Annablume, 2006.

HARVEY, David. A Produção Capitalista do Espaço. São Paulo: Annablume, 2005.

IGNARRA, Luiz Renato. Fundamentos do turismo. 2.ed. São Paulo: Thompson Pioneira, 2003.

LEFEBVRE, Henri. Estrutura social: a reprodução das relações sociais. In: MARTINS, José de Souza; FORACCHI, Marialice Mencarini. Sociologia e sociedade: leituras de introdução à sociologia. Rio de Janeiro: Livros técnicos e científicos, 1977.

O direito à cidade. São Paulo: Centauro, 2001.

Espaço e política. Belo Horizonte: Editora UFMG, 2008.

MASCARENHAS, Fernando. Em busca do ócio perdido: idealismo, panacéia e predição histórica à sombra do lazer. In: PADILHA, Valquíria (Org.). Dialética do lazer. São Paulo: Cortez, 2006.

NAVARRO, Vera Lúcia. Trabalho, saúde e tempo livre sob os domínios do capital. In:

PADILHA, Valquíria. Tempo livre e capitalismo: um par imperfeito. Campinas, SP: Editora Alínea, 2000.

(Org.). Dialética do lazer. São Paulo: Cortez, 2006.

SÁNCHEZ GARCIA, F. Cultura e renovação urbana: a cidade-mercadoria no espaço global. In: Espaço e cidade: conceitos e leituras Org. Evelyn Furquim Werneck Lima, Miria Roseira Maleque. $2^{\mathrm{a}}$. Ed. Rio de Janeiro: 7Letras, 2007. 
SANTOS, Milton. A urbanização desigual. Petrópolis: Vozes, 1980.

. Território e sociedade: entrevista com Milton Santos. 2. ed. São Paulo: Editora Fundação Perseu Abramo, 2004.

URRY, John. O Olhar do Turista: lazer e viagens nas sociedades contemporâneas. São Paulo: Studio Nobel, Sesc. 2001.

VAINER, C. Pátria, empresa e mercadoria. Notas sobre a estratégia discursiva do planejamento estratégico urbano. In: ARANTES, Otilia; VAINER, Carlos; MARICATO, Ermínia. A cidade do pensamento único. Desmanchando consensos. Petrópolis: Vozes, 2000.

VIEITEZ, Candido Giraldez. Marx, o trabalho e a evolução do lazer. In: BRUHNS, Heloisa Turini (Org.). Lazer e ciências sociais: diálogos pertinentes. São Paulo: Chronos, 2002.

Recebido em: 30/08/2012 (1 ${ }^{\mathrm{a}}$ versão) $10 / 01 / 2013$ ( $2^{\mathrm{a}}$ versão)

Aprovado em: 06/05/2013 